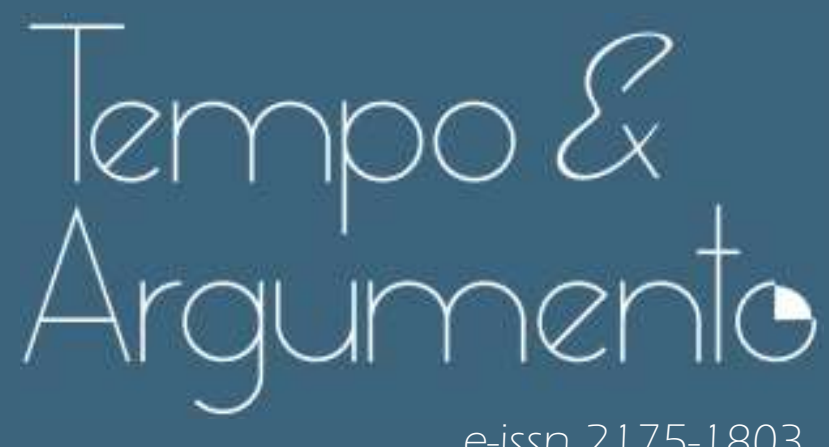

e-issn 2175-1803

\title{
Uma flor com História: ensinar o fim da ditadura em Portugal a partir de uma narrativa literária
}

*. Ana Isabel Moreira

Doutora em Educação pela Universidade de Santiago de Compostela - Espanha. Investigadora do Centro de Investigação Transdisciplinar "Cultura, Espaço e Memória». Porto - PORTUGAL

cienciavitae.pt/4315-7FCF-80C0 ana_m0reira@hotmail.com

(D) orcid.org/0000-0002-6757-8005

1. Maria Elisa Sousa

Doutora em Ciências da Educação pela Universidade do Minho - Portugal.

Professora da Escola Superior de Educação do Instituto Politécnico do Porto.

Porto - PORTUGAL

ese.ipp.pt

elisa.elisasousa@gmail.com

(D) orcid.org/0000-0002-8968-970X

w. Pedro Duarte

Doutor em Educação pela Universidade de Santiago de Compostela - Espanha.

Professor da Escola Superior de Educação do Instituto Politécnico do Porto.

Porto - PORTUGAL

cienciavitae.pt/8B 15-7C50-C2AD

pedropereira@ese.ipp.pt

(D) orcid.org/0000-0002-3048-6959

Para citar este artigo:

MOREIRA, Ana Isabel; SOUSA, Maria Elisa; DUARTE, Pedro. Uma flor com História: ensinar o fim da ditadura em Portugal a partir de uma narrativa literária. Tempo e Argumento, Florianópolis, v. 13, n. 33, e0 106, maio/ago. 2021.

de http://dx.doi.org/10.5965/2175180313332021 e0106

Recebido: 28/02/2021

Aprovado: 18/05/2021 


\title{
Uma flor com História: ensinar o fim da ditadura em Portugal a partir de uma narrativa literária
}

\begin{abstract}
Resumo
O ensino da História afirma-se, hoje, como um importante contributo para a formação integral das mais jovens gerações, como facilitador de uma mais consciente compreensão das realidades sociais e culturais contemporâneas, como potenciador de competências várias para a interpretação dos assuntos históricos e, por conseguinte, da participação democrática mais esclarecida. Por sua vez, a educação literária pode, se assim for entendido, proporcionar uma multiperspetivada e humana forma de analisar e compreender os fenómenos sociais, a história comum de todos os dias, os diferentes tempos e lugares. Dessa interação evidente entre áreas do saber diferentes percebe-se a possibilidade de se desenvolverem, com coerência, dinâmicas de articulação curricular. Nesse sentido, a presente investigação resulta de um estudo desenvolvido com crianças portuguesas do 6. ano de escolaridade, que, em sala de aula, estudaram os conteúdos relacionados com a Revolução democrática do 25 de abril de 1974 a partir de uma obra literária infanto-juvenil - "História de uma Flor", de Matilde Rosa Araújo. Os dados evidenciam as potencialidades formativas da dinâmica de articulação curricular concretizada, uma vez que as crianças foram capazes de fazer uma leitura individual, com significado, do texto literário selecionado e, através dela, apropriarse de outros conhecimentos históricos além dos substantivos.
\end{abstract}

Palavras-chave: Educação Histórica; literatura; história; articulação curricular; Portugal.

\section{A flower with History: teaching the end of the dictatorship in Portugal through a literary narrative}

\begin{abstract}
The teaching of History asserts itself, today, as an important contribution to the integral formation of younger generations, as a facilitator of a more conscious understanding of the contemporary social and cultural realities, as an enhancer of various skills for the interpretation of historical matters and, therefore, of a more enlightened democratic participation. On the other hand, the intentional use of Literature might provide a multiperspective and human way of analyzing and understanding social phenomena, everyday common history, different times and places. Through that evident interaction between areas of knowledge, it is possible to understand the possibility of developing, with coherence, dynamics of curricular articulation. In that sense, this investigation results from a study developed with Portuguese children attending the 6th grade who, in the classroom, studied the contents related to the democratic Revolution of April 25th, 1974 through a literary work - "História de uma Flor" ("History of a Flower"), written by Matilde Rosa Araújo. The collected data evinces the formative potentialities of the realized dynamic of curricular articulation, since the children were able to make an individual reading, with meaning, evidencing the understanding of the selected literary text and, through it, appropriating other historical knowledge besides dates and names.
\end{abstract}

Keywords: History Education; literature; history; curriculum articulation; Portugal. 


\section{Introdução}

No panorama atual, o de uma realidade que parece organizada em "países de crianças" e onde "qualquer formulação frásica mais consistente deixa de lado metade da humanidade que já não estará a entender nada" (MÃE, 2021), a aprendizagem da História alcança um papel de realce se entendida como um contributo para que o ser humano seja capaz de conferir significado(s) à vida social de tempos vários.

Quando, aparentemente, “ainda falta ensinar quase tudo” (MÃE, 2021), não afirmamos a anterior ideia num sentido impositivo de certa ideologia preferida ou numa perspetiva revisionista face a elementos que se querem esquecer ou, por algum motivo, alterar.

Com outro intuito, assumimos o ensino da História como uma prática fundamental para, com base em princípios científicos e epistemológicos válidos, se favorecer a formação de sujeitos esclarecidos, questionadores e respeitadores da pluralidade.

E se é verdade que História 'rima' com Memória, também o é que pode articular-se com outras áreas do saber e, assim, potenciar uma distinta aquisição de saberes e um particular desenvolvimento de competências. Neste caso, sublinhamos uma outra 'rima' exequível entre História e Literatura.

De facto, fazendo uso de uma obra da literatura infanto-juvenil, enquanto eixo estruturante para um percurso de articulação curricular, como neste texto adiante se relata, é possível medrar a consciência histórica dos mais jovens cidadãos ou, dito de outro modo, otimizar um raciocínio mais completo e que não assenta na memorização mecânica ou na replicação inócua.

Para dar forma a este que é também um projeto de pesquisa, na aula de História (e Geografia de Portugal), os alunos do 6. ano de escolaridade (10/11 anos de idade) de uma turma da primeira autora deste artigo aprenderam sobre o Estado Novo - o período ditatorial português do século XX -, bem como sobre a sua relação de causalidade com a ação militar e popular que originou a revolução democrática de 1974. No entanto, não tiveram o caderno diário e o manual escolar como recursos primeiros para o seu trabalho de estudantes. Aqueles 
foram intencionalmente substituídos por Matilde Rosa Araújo e pela sua "História de uma Flor", a par de um guião orientador da leitura dessa obra literária.

E, assim, um texto com qualidade estética e formal não só potenciou a prática da leitura e da escrita útil e fruitiva, como também favoreceu o exercício de certo pensamento histórico. Ao longo das próximas páginas, pretendemos evidenciá-lo cruzando as bases conceptuais que orientam a nossa reflexão sobre a temática investigada com os dados empíricos recolhidos.

No final, porventura estaremos aptos a dar resposta à questão de investigação que tomamos como mote para esta pesquisa: que implicações formativas podem resultar de uma articulação curricular entre a História e a Literatura?

\section{Ensinar História (na atualidade)}

Conceptualmente, optamos por enquadrar o nosso texto a partir de três pontos fundamentais tendo em conta o conteúdo e propósito da investigação: os rumos mais atuais da educação histórica, uma (possível) faceta da articulação curricular e a ligação intrínseca entre História e Literatura.

\subsection{Dos conhecimentos à consciência histórica desenvolvida}

\subsubsection{Algumas ideias prévias}

Desde logo, tanto no âmbito epistemológico como naquele que se direciona para a didática, importa tomar em consideração que a "História, por definição, relaciona-se com incertezas, inferências e probabilidades" (SMITH; JACKSON, 2021, p. 154, tradução nossa). Por conseguinte, a abordagem honesta da mesma, num sentido analítico e reflexivo, terá de ocasionar um conhecimento que é abrangente e, assim, capaz de contemplar os aspetos disruptivos, contraditórios, criticáveis até, nomeadamente quando associados a um determinado país e ao seu percurso ao longo do tempo (NORDGREN, 2017).

No que concerne àquele que pode ser o processo de ensino e de aprendizagem desse tempo pretérito que, inevitavelmente, se relaciona com a 
realidade presente e, ainda, com certo futuro hipotético, a asserção anterior será sinónimo da História como construção, investigação e problematização dos fenómenos e, por tal, contributo para a formação intercultural e multiperspetivada de todos quantos a estudem (BARCA, 2019a; BARTON; LEVSTIK, 2004).

De acordo com Chapman (2010, 2021), a aprendizagem da História que não é fixa, inquestionável ou sempre positiva pressupõe, então, que os jovens estudantes entendam que há uma panóplia de possibilidades de interpretação, e revisão, que ultrapassam a contemporaneidade por eles (em parte) conhecida.

Por outras palavras, contemplando também as idades muito jovens, embora às vezes se pense que aí não se alcançam outros níveis de pensamento (histórico), é possível conferir à disciplina um valor formativo de realce, em particular para o desenvolvimento de uma literacia própria (LEE, 2016). ISSo, independentemente de se saberem os elementos "do conhecimento histórico [que são] contra-intuitivos e desafiadores" (LEE, 2005, apud CHAPMAN, 2021, p. 11, tradução nossa).

Uma literacia histórica que permite a perceção de um mundo que não se restringe ao aqui e agora (LEE, 2016); a compreensão dos avanços e retrocessos, sucessos e derrotas, causas e consequências, mudanças e continuidades ocorridos ao longo do tempo (SEIXAS; MORTON, 2013) ou da realidade atual que não se circunscreve a um país de origem ou a uma língua materna; a constatação de que há, como sempre houve, os outros, seres humanos também com desejos e receios, sonhos e dificuldades, uma identidade que é tão sua quanto a de cada um. E que, por consequência, só pode ser o mote para atitudes intelectual e socialmente tolerantes, não paternalistas e distantes de rejeições não ponderadas.

Desta forma, e tal como Wineburg (2001) já perspetivava no início do século, distanciam-se os sujeitos do senso comum, tantas vezes preferido para se perceber o passado, aproximando-os, antes, da unnatural forma de pensar que a História nos proporciona. Algo relevante se, e de acordo com a opinião de Isabel Barca (2019a), assumirmos a crescente necessidade do saber histórico, 
sobretudo para que o ser humano, cidadão num contexto, experiencie a oportunidade de se entender e de melhor atuar na sua vida em sociedade.

\subsubsection{Educação histórica com sentido(s)}

$\mathrm{Na}$ contemporaneidade, cada vez mais do que uma acumulação de saberes restritos e contáveis, com base nos princípios que vão sustentando uma formação histórica reconhecida como cientificamente válida, privilegia-se a aprendizagem que decorre do diálogo a partir de uma argumentação assente na evidência disponível (BARCA, 2019b; COUNSELL et al., 2018; LEE, 2016; SCHMIDT; URBAN, 2018). Ou, por outras palavras, tende-se a enfatizar o ensino da genuína interpretação histórica que envolve a consideração de inúmeros pontos de vista em simultâneo e certa rejeição de narrativas únicas, mais ou menos heróicas (BARCA, 2019a).

Deste modo, com alguma clarividência, afirma-se uma orientação para as aulas lecionadas no seio daquela componente curricular que, segundo Nordgren (2017), pode ser contributo para o desenvolvimento de uma certa crítica distanciada e de algumas habilidades analíticas.

Recorrendo a uma explicação complementar, a aprendizagem da História terá de permitir, a qualquer um, o aprimoramento de processos de pensamento específicos, sobretudo numa espécie de reading like a historian [ler como um(a) historiador(a) (WINEBURG, 2001). Com efeito, a compreensão dos conteúdos implica estratégias próprias, quase similares à prática de um historiador, que permitem a elaboração de um conhecimento específico, assente em conexões, generalizações e interpretações variáveis.

Essas mencionadas habilidades de raciocínio podem enumerar-se por entre o sentido crítico, fundamentado e que ultrapassa as opções óbvias e copiadas; a seleção e organização da informação para uma argumentação sustentada face a perspetivas outras, mas igualmente pertinentes (BARCA, 2019b; CHAPMAN, 2010); o reconhecimento de uma cidadania plural mais do que do etnocentrismo (TORRES SANTOMÉ, 2015); a compreensão de identidades mais amplas do que um ideológico nacionalismo banal (BILLIG, 2014) e redutor (MANSFIELD, 2019). 
De há uns anos a esta parte, o processo de ensino e de aprendizagem da História enformado pelos contornos que aqui temos clarificado, foca-se "na natureza provisória do conhecimento e na necessidade de os alunos compreenderem a sua construção a partir de evidências, argumentos e interpretações" (COUNSELL et al., 2018, p. 2, tradução nossa).

Essa mesma perspetiva espera-se nas salas de aula, numa aproximação entre a teoria e a prática, sob a forma de estudantes que querem saber a origem e a plausibilidade da informação (histórica) com a qual se encontram quotidianamente, que adotam uma atitude questionadora perante as fontes disponíveis ou problematizadora das verdades partilhadas nas redes sociais (CHAPMAN, 2021; LEE, 2016; SCHMIDT; URBAN, 2018), que assumem a memória como uma de várias premissas do conhecimento. Mais ainda, que não se tornam complacentes com desculpas ou lamentos pelos tempos idos, nem mesmo com vangloriações desmedidas e desadequadas (BILLIG, 2014) e, com outra postura cidadã construída, optam por considerar, como saber construído, todos os momentos históricos, sejam os mais positivos, sejam aqueles que mais dúvidas suscitam (MANSFIELD, 2019).

Em concomitância, porventura pode identificar-se ali a oportunidade para se promover uma educação em/para a cidadania ponderada, argumentativa e responsável, bem como um incentivo para a busca do bem-estar coletivo, mundial (BARTON; LEVSTIK, 2004), sobretudo pela assunção da intertemporalidade, pela consciência ética, pela ponderação sustentada e que liga múltiplas causas e efeitos. E, de alguma forma, poderá ser esta emancipação intelectual a evitar a sujeição a interpretações do mundo pelos olhos de alguém (quantas vezes pouco imparciais), a submissão a uma qualquer perspetiva ou ideologia unilateralmente imposta, a auto-centração assente no patriotismo como tem de ser e na inabilidade para equacionar (n)o lugar de outros.

Quase como ponto final, no meio de muitas reticências que sempre há, seguimos o mesmo sentido que a pesquisa em Educação Histórica e os seus investigadores vão corroborando. Referimo-nos aqui ao sentido da aprendizagem de um conhecimento competente, ou seja, potenciador de um outro modo de pensamento (epistemologicamente consciente), mais capaz de proporcionar um 
entendimento esclarecido de si e de outros à sua volta (LEE, 2016). Por isso, capaz de favorecer uma leitura significativa de um mundo que é incerto e, depois, uma intervenção intencional e refletida nessa sociedade onde cada um marca presença como cidadão.

\subsubsection{Para além dos conhecimentos substantivos}

Pela visão de Jörn Rüsen (2019), a História traduz-se numa significativa interrelação entre passado, presente e futuro. Ou seja, a sua mobilização não remete apenas para o tempo pretérito, mas favorece a interação com as necessidades e fragilidades atuais, marcando ainda o amanhã (NORDGREN, 2016).

Também por essa razão, o conhecimento esclarecido da História, na realidade escolar, não subsiste pela mera aquisição de saberes substantivos e exige, de outro modo, o desenvolvimento de um raciocínio mais sofisticado e pelo qual a informação factual é situada e compreendida (WINEBURG, 2001).

Importa, pois, distinguir dois elementos fundamentais e que, didaticamente, não podem ser arredados da discussão sobre a História que se ensina e que se aprende na sala de aula. Por um lado, surgem os conhecimentos substantivos, coincidentes com conceitos, datas e factos históricos concretos, que permitem representar o passado; por outro, destacam-se os conceitos metodológicos (ou de "segunda ordem") sob a forma de capacidades e competências estratégicas que organizam e explicam os saberes substantivos e ocasionam a resposta a questões históricas ou o entendimento do(s) tempo(s) de forma mais ampla. Este modo de pensar historicamente inclui, entre outras habilidades, a busca, seleção e análise de fontes, a empatia ou o reconhecimento da (multi)perspetiva histórica (CHAPMAN, 2021; COUNSELL et al., 2018; SEIXAS; MORTON, 2013).

Crê-se, de facto, que a aprendizagem desses saberes sobre História será o ponto de partida privilegiado para a desconstrução de mitos homogeneizadores e excludentes e para o estabelecimento de relações mais significativas entre os tempos pretérito, presente e, eventualmente, futuro (NORDGREN, 2016; RÜSEN, 2010). 
Talvez se possa afirmar, de forma mais concreta e direta, que será um contributo inequívoco para o desenvolvimento de uma consciência histórica intercultural, cosmopolita e humanista (BARCA, 2019a; RÜSEN, 2010). Isto é, não se pode negar ao ser humano a capacidade de estabelecer relações significativas entre momentos distintos, no contexto da vida prática, considerando-se as especificidades próprias de acontecimentos que decorrem num particular ambiente social e cultural.

Com efeito, a necessidade de atribuição de um significado a um fluxo que não é controlável (RÜSEN, 2010; 2019) vai emergindo como potencialmente relevante para cada qual. Sobretudo se atendermos àquilo que Seixas e Morton explicitam com particular clareza:

explicar factos históricos de modo adequado implica o estabelecimento de relações causais dinâmicas que envolvem diferentes escalas temporais (longo/médio/curto prazo) e diferentes dimensões da vida humana (social, económica, cultural, militar, etc.). (SEIXAS; MORTON, 2013, apud CHAPMAN; GEORGIOU, 2021, p. 77, tradução nossa)

O desenvolvimento dessa consciência histórica, por sua vez, tende a seguir uma sequência lógica e progressivamente mais complexa, num processo que traduz a ampliação do entendimento individual relativamente à dimensão temporal, à relevância histórica, às questões éticas e, até mesmo, a uma identidade histórica que pode ser, ou não, assumida (BARCA, 2019a; RÜSEN, 2010; SEIXAS; MORTON, 2013).

Depois, já como atuação propriamente dita, será expectável que os estudantes, fazendo uso daquela literacia própria e da consciência histórica agora assumida, alcancem uma compreensão mais ampla, diacrónica e democrática do mundo. E, desta base de habilidades cognitivas, avancem para a complexa explicação dos fenómenos históricos, se mais quiserem do que só rememorar meia dúzia de nomes e/ou datas, antes pretendendo uma participação tangível, com crítica e reflexão, nas sociedades diversas, atuais, onde circulam inúmeras perspetivas construídas (BARCA, 2019b). 


\subsection{Currículo, educação histórica e educação literária: uma interação improvável?}

Como discutido ao longo das páginas anteriores, a aprendizagem histórica vai beneficiando, a par de outros tantos contributos, a maturação intelectual e cívica de cada cidadão, por mais jovem que ele seja.

Assume-se, hoje, que saber sobre História é permitir certa interação quotidiana com tal disciplina científica, intelectualmente complexa e desafiante, para uma mais consciente compreensão e ação no presente, também como forma de construção de outro(s) futuro(s).

Essa perspetiva, no domínio da educação histórica, inscreve-se numa corrente mais alargada que salienta a importante relação entre os conhecimentos, as competências e a agência dos estudantes, assim como uma mais estreita ligação entre o conhecimento escolar e os saberes que marcam a vida de cada aluno (LEITE, 2012; ROSALES LÓPEZ, 2009).

\subsubsection{O que entendemos como articulação curricular}

Pese embora o referido, ainda não se dissiparam totalmente as lógicas disciplinares, que fragmentam a experiência escolar (BEANE, 2003; MORGADO; SILVA, 2019; TORRES SANTOMÉ, 2015). Justificadas, em parte, pela tradição escolar ocidental, constatam-se estruturas curriculares pouco dialogantes e, por isso, desconexas, centradas no enciclopedismo estéril e de reduzida implicação na experiência social dos estudantes (ROLDÃO, 2017).

Segundo Beane (2003), Roldão e Almeida (2018), esse desenho curricular resulta da progressiva especialização científica. De facto, a afirmação de determinadas disciplinas académicas/científicas foi, com maior ou menor expressão, transportada para as diferentes realidades educativas, estabelecendo-se um cânone de disciplinas escolares. De acordo com Torres Santomé (2015), essa marca histórica confere às organizações educativas a imagem de reinos de artificialidade, caracterizada por uma rígida compartimentação, mais ou menos arbitrária, auto-justificativa e que ocasiona o empobrecimento curricular. 
Num outro sentido, são vários os especialistas que têm apontado para um enquadramento curricular de maior articulação, fundamental para potenciar uma apropriação cultural mais globalizante (BEANE, 2003; LEITE, 2012; MORGADO; SILVA, 2019; ROSALES LÓPEZ, 2009).

Importa clarificar, porém, que este enquadramento não visa a desconsideração dos saberes científicos de matriz disciplinar, na verdade, entendidos como basilares para qualquer processo de ensino e para qualquer sistema de educação (ROLDÃO; ALMEIDA, 2018). Antes se faz a apologia de uma estrutura curricular que, a partir desse conhecimento científico especializado, permita a construção de experiências educativas integradas, para que, segundo Torres Santomé (2015), desde os primeiros instantes os alunos compreendam as intenções e razões das tarefas escolares que têm de realizar.

Além disso, a mesma poderá reconhecer e legitimar os conhecimentos dos alunos, nomeadamente aqueles que se constroem fora da realidade escolar, na vivência do dia a dia (BEANE, 2003; LEITE, 2012). E isto significa, por outras palavras, que a articulação curricular acontece, também, pela relação entre a escola e a experiência de vida dos estudantes, integrados numa comunidade local. Uma ideia que Morgado e Silva (2019) apresentam como articulação curricular lateral.

Para o presente trabalho importa discutir, também, o que se preconiza como articulação curricular horizontal (MORGADO; SILVA, 2019), ligada à ideia de interdisciplinaridade. Essa articulação horizontal pressupõe que as barreiras tradicionais das disciplinas escolares sejam (total ou parcialmente) quebradas, potenciando a pluralidade interativa de saberes (BEANE, 2003; LEITE, 2012), como forma de "romper uma lógica fragmentária instituída" (ROLDÃO; ALMEIDA, 2018, p. 43).

As dinâmicas de interdisciplinaridade são várias, podendo associar-se à análise multidisciplinar de um tema, a uma unidade didática de duração variável, à elaboração de um projeto ou à resolução de um problema que integra o contributo de mais do que uma disciplina escolar ou científica, à utilização de um mesmo recurso didático em distintas componentes curriculares, entre outras (ROSALES LÓPEZ, 2009; TORRES SANTOMÉ 2015). E essas dinâmicas precisam 
de contemplar dois princípios em particular: por um lado, evitar situações de instrumentalização de uma componente curricular em relação a qualquer outra; por outro, serem assumidas na ótica dos estudantes, envolvidos nas distintas experiências escolares.

Em suma, destaca-se a relevância de práticas de articulação curricular, porquanto as mesmas possibilitam uma mais complexa relação com o conhecimento, e, por inerência, com a própria sociedade (BEANE, 2003; ROLDÃO; ALMEIDA, 2018; TORRES SANTOMÉ, 2015).

\subsection{História (e Geografia) de Portugal como disciplina escolar}

Como apresentado, os processos de articulação curricular podem não implicar a rutura total com as disciplinares escolares existentes (ROSALES LÓPEZ, 2009). Neste sentido, a História está presente no currículo prescrito português e não se questiona, ou põe em causa, tal facto, antes se vai debatendo o enfoque principal em determinados conteúdos, no desenvolvimento de competências, em certas pedagogias tidas como didaticamente consistentes (BARCA, 2019b).

$\mathrm{Na}$ verdade, e tal como afirmaram Barton e Levstik (2004), a História, nomeadamente ensinada e aprendida na escola, exige sempre escolhas, pois a prática educativa sustenta-se nesta ou naquela estratégia e recai neste ou naquele assunto. Depois, embora se defenda, com base na investigação cada vez mais consolidada, que "o ensino da História desempenha um papel fundamental para fazer face aos desafios políticos, culturais e sociais" (CONSELHO DA EUROPA, 2018, p. 5) da atualidade, não raras vezes resvala-se, na realidade prática, para o investimento na preparação para provas de avaliação externa ou nos recursos que sempre se utilizaram e que estão logo ali.

Ainda assim, os próprios documentos oficiais mais recentes, em Portugal, parecem querer contrariar tais tendências, às vezes, aparentemente incontornáveis, salientando-se, por exemplo, no texto de 2017, intitulado Perfil dos Alunos à Saída da Escolaridade Obrigatória, a importância de se adotarem recorrentemente "atividades que permitam ao aluno fazer escolhas, confrontar 
pontos de vista, resolver problemas e tomar decisões com base em valores" (MARTINS et al., 2017, p. 31). De alguma forma, decisões que favorecem, no que à História diz respeito, o aprimoramento daquelas já relatadas competências do pensamento histórico, portanto fundamentais para, nunca negligenciando o diálogo e a cooperação, "os jovens se tornarem participantes ativos de uma cultura democrática [...] na esfera pública" (CONSELHO DA EUROPA, 2018, p. 6).

No que concerne em específico ao 2. Ciclo do Ensino Básico, nível de ensino contemplado na investigação aqui apresentada, a História continua a ser a disciplina que se alia à Geografia, porque assim, segundo as diretrizes atuais, os estudantes vivenciam a oportunidade de "adquirir um conhecimento diacrónico da história e do território de Portugal" e de "reconhecer a identidade espácio-temporal de Portugal nos seus aspetos mais relevantes". Tais aprendizagens, porventura, desse modo mais "globalizantes e significativas" (APRENDIZAGENS ESSENCIAIS, 2018, p. 2-3'), serão pois um outro contributo de realce para uma formação humanista e que toma em consideração "uma sociedade centrada na pessoa e na dignidade humana como valores fundamentais" (MARTINS et al., 2017, p. 6).

Com efeito, sem a apreensão de narrativas inalteráveis ou revisionistas, mas mobilizando as múltiplas perspetivas que respeitam "valores intelectuais como a busca da verdade, a fundamentação dos argumentos e o respeito pelas fontes" (CONSELHO DA EUROPA, 2018, p. 10), tal aprendizagem assumir-se-á como indispensável no quotidiano daqueles que, pese embora jovens, são também agentes da História, e não meros espectadores do acontecido outrora.

E logo ali, na sala de aula, afirmar-se-ão como cidadãos críticos e reflexivos, particularmente sensíveis às inverdades que pululam nas redes sociais, nos meios de comunicação, nas conversas de circunstância, pois ainda cientes do "impacto histórico de rumores e conteúdos fabricados" (CONSELHO DA EUROPA, 2018, p. 20). Por outras palavras, e finalizando com aquele Perfil dos Alunos à Saída da Escolaridade Obrigatória, a disciplina de História no espaço social que é a escola pode consolidar, com consequência, essa intenção de 
“formar pessoas autónomas e responsáveis" (MARTINS et al., 2017, p. 5), que sabem mais do que apenas replicar uns quantos nomes de reis e umas quantas datas de batalhas.

\subsection{A Literatura e sua relação com a História que se quer ensinar}

Nós, seres humanos, somos contadores de histórias inatos e gostamos imenso de contar histórias sobre o início das coisas. (DAMÁSIO, 2017, p. 18)

Esta afirmação de António Damásio poderá iluminar, desde logo, a quase natural relação entre Literatura e História, muito em particular, a História que se pretende ensinar, concorrendo para sublinhar a linha de pensamento que tem vindo a ser exposta ao longo deste artigo. Na verdade, quer a Literatura, quer a História colocam a vida perante os nossos olhos, ajudam a compreender o presente, com viagens ao passado, para saber por onde começamos e, quiçá, supor para onde vamos, para projetar futuros que se poderão transformar em presentes mais próximos do que a ficção esperaria.

A Literatura assume uma relevância inquestionável "na modelização do mundo, na construção dos universos simbólicos, na convalidação de sistemas de crenças e valores" (SILVA, 1981, p. 14). Nela se encontra a vida, contacta-se com seres humanos que experimentam sentimentos e emoções, alcança-se lugares, espaços, épocas, tempos e circunstâncias desses mesmos tempos, podendo considerar-se que é também através da Literatura que se encontra respostas possíveis para dúvidas e inquietações, oportunidade para a evasão, para buscar o alimento que a imaginação reclama, a agilidade para lidar com uma sociedade repleta de constrangimentos, conflitos e limitações.

O texto literário comporta visões do mundo, crenças e capacidades, um olhar crítico de alguém que capta e regista a sua interpretação, as suas descobertas, as suas propostas, procurando conferir sentido a uma narrativa que veicula valores, condutas e atitudes e que faz aceder a outros patamares e a outros mundos. Assim pode contribuir para fomentar nos leitores "um discernimento do mundo e um posicionamento perante a realidade" (ZILBERMAN, 1987, p. 27), perante as realidades que nos cercam, perante a 
(in)diferença, questionando, problematizando, resolvendo conflitos, fazendo paragens, recuos, avanços, conferindo ao leitor esse passaporte vitalício que the permite voltar, de novo, ao início da viagem as vezes que entender.

Ao invés da vida humana, que tem um fim, sem possibilidade de voltar ao início quando ela termina, a Literatura, a ficção, através das páginas por onde caminhamos, e podemos mesmo voar, permite-nos chegar ao fim e recomeçar essa viagem quantas vezes quisermos, no tempo que quisermos (MANGUEL, 1998). E é essa possibilidade de repetidas e voluntárias viagens, mais próximas ou mais distantes no tempo, que também alicerça o desenvolvimento integral do ser humano, contribuindo para a construção da sua maturidade intelectual e cívica, como atrás foi já referido.

Como afirmamos antes, a vida, vivida, contada, recreada é a fonte que alimenta a Literatura e está no coração da História, na medida em que é de vida que se fala quando se estuda o passado da Humanidade, um passado mais longínquo ou mais próximo, que mostra o que fazem os seres humanos, em determinadas circunstâncias, num espaço e num tempo, mais ou menos, concretos. São também acontecimentos do passado, mais distante ou mais próximo, protagonizados pela Humanidade que alimentam a Literatura e permitem ficcionar a realidade e o futuro, pelo recurso à retórica, ao imaginário, ao sortilégio que nos deslumbra e nos faz evadir. A Literatura, como forma de arte que é, oferece o apaziguamento, a leveza e o humor que nem sempre a realidade comporta:

[...] no seu desejo de reconciliar as contradições apresentadas pelo sofrimento, pelo medo e pela fúria, e na busca do bem-estar, os seres humanos optaram pela maravilha e pelo deslumbramento e descobriram a música, a dança e a pintura, e a literatura. (DAMÁSIO, 2017, p. 19)

A Literatura é vida e dela se alimenta. É resultado de contextos e de circunstâncias, reproduz situações e acontecimentos, comporta visões do mundo, marcadas pela visão do sujeito que as produz, capaz de registar de forma crítica, hermenêutica, criativa e prospetiva o mundo à sua volta, permitindo leituras e interpretações múltiplas, subjetivas, marcadas pela visão do leitor, proporcionando sentimentos e emoções multifacetadas. 
A História, por sua vez, poderá constituir uma fonte para a produção literária, cuja intenção não é o estudo impessoal, factual de um determinado acontecimento histórico, mas recreá-lo, introduzindo os recursos estéticos e linguísticos que o aproximam de uma lógica criativa, da dimensão de jogo e de descoberta, no universo de todas as possibilidades que é a ficção.

Este diálogo entre a Literatura e a História, de aproximação e distância feita, torna-se ainda mais crucial quando nos questionamos quanto à História que se pretende ensinar. Parece-nos incontornável a relevância da Literatura, em particular das narrativas relacionadas com acontecimentos históricos, para reforçar os propósitos de uma História que fornece ferramentas - como a argumentação e contra-argumentação ou a formulação de hipóteses - para conhecer o passado, mas com um olhar crítico, para o compreender e relacionar com o presente, com a vida e as suas circunstâncias.

Através da Literatura, emergem as múltiplas possibilidades de interpretação, de confronto de opiniões, a possibilidade de tomar partido, de se colocar no lugar do outro, desenvolvendo a empatia, a capacidade de relacionar tempos e acontecimentos, de delimitar ficção e 'realidade', de poder até mudar o curso dos acontecimentos para obter outros resultados, de aprender a rir dos assuntos mais sérios, ser capaz de identificar marcas de ironia e de humor. Ensinar História a partir da Literatura é também promover a capacidade de relacionar passado e outros tempos, de compreender o sentido que o passado faz para nos situarmos no aqui e agora das nossas vidas e em cenários futuros ainda em construção.

História e Literatura articulam-se para fazer chegar mais longe, para dessacralizar o passado e a veneração, aprendendo antes a tomar consciência da participação cidadã e a valorizar a condição humana, colocando os seres humanos como prioridade, num mundo mais habitável e digno, que a escola desejavelmente deveria ajudar a tornar-se realidade.

Dois saberes que se articulam, conhecimentos científicos que dialogam para, como foi apresentado em pontos anteriores, tentar construir e facultar aos alunos experiências integradoras, procurando contribuir para que os alunos atribuam sentido às atividades propostas e compreendam a sua razão de ser 
(TORRES SANTOMÉ, 2015). Antes de mais, narrativas de Humanidade, e dela se tem de fazer cada vez mais o ensino e a escola, pelas pontes que souber criar e pelos muros que for capaz de derrubar.

\section{Da narrativa literária à narrativa histórica - metodologia}

\subsection{Um estudo de caso}

A nível metodológico, este é um estudo de caso (YIN, 2018) que envolveu uma turma do 6.- ano de escolaridade de uma escola privada, de cariz religioso, do distrito do Porto, em Portugal. As crianças que frequentam esta instituição, raparigas e rapazes, têm idades compreendidas entre os meses de idade e os 12 anos e provêm de contextos sem evidência de carências económicas.

No ano letivo 2019/20, ali, e durante uma unidade didática constituída por três aulas de História e Geografia de Portugal (ca. 150 minutos), a atividade foi proposta pela docente (uma das autoras deste artigo, como mencionado na introdução): a partir da obra literária infanto-juvenil, da autoria da portuguesa Matilde Rosa Araújo, "História de uma Flor"2, estudar os antecedentes ocasionadores da ação revolucionária de 25 de abril de 1974, assim como as consequências imediatas desse acontecimento histórico.

A leitura do livro havia de acontecer coletivamente, pela voz orientadora da professora - que, uma vez mais, recordamos ser a primeira autora do presente texto -, somando-se à mesma o preenchimento, ora individualmente, ora em diálogo com os pares, de um guião de leitura elaborado pela docente especificamente para as sessões. Como fonte de informação a consultar, os estudantes tinham à sua disposição o manual escolar da disciplina. A interação coletiva sobre as perguntas e respostas foi mobilizada para a explicitação dos conteúdos científicos em estudo, assim como para o desenvolvimento de competências do pensamento histórico.

Para a interpretação dos apontamentos redigidos pelos alunos, concretizada mais à frente, optamos por uma análise de conteúdo (BARDIN, 2011),

\footnotetext{
2 A obra escolhida data de 2008, tendo sido publicada aquando das comemorações do 34.은 aniversário da Revolução do 25 de abril de 1974. A autora é uma das mais importantes escritoras portuguesas de Literatura para a Infância e a Juventude.
} 
deste modo conferindo sentido, no âmbito da didática da História, àqueles registos individuais. Também por razão desta última intenção mencionada, apresentamos, adiante, um cruzamento entre as próprias asserções dos participantes e os elementos conceptuais que sustentaram a nossa pesquisa.

Pela natureza do trabalho concretizado e, ainda, pelas características dos dados recolhidos, pareceu-nos mais significativo, no que à dimensão investigativa se refere, recorrer a uma apreciação interpretativa, coincidente com uma abordagem qualitativa (FLICK, 2015), dos vários elementos considerados.

\subsection{Participantes}

Mais uma vez, destaca-se a participação de 14 alunos (de um total de 15) de uma turma do 6. ano de escolaridade, na disciplina de História e Geografia de Portugal.

Os mesmos, com idades compreendidas entre os 10 e os 11 anos, tinham no seu horário, no aludido ano de 2019/20, três horas semanais (55' + 55' + 55') da referida componente curricular obrigatória. De salientar, novamente, que a dinamização da atividade teve lugar numa instituição privada do norte de Portugal.

Para a recolha de dados, considerou-se a planificação elaborada e, por isso, as aulas nas quais se pretendia abordar os conhecimentos, capacidades e atitudes que o documento oficial das Aprendizagens Essenciais clarifica do seguinte modo:

Sintetizar as principais características do Estado Novo, nomeadamente a ausência de liberdade individual, a existência da censura e de polícia política, a repressão do movimento sindical e a existência de um partido único.

Reconhecer os motivos que conduziram à revolução do 25 de abril, bem como algumas das mudanças operadas. (APRENDIZAGENS ESSENCIAIS, 2018, p. 8-9)

A partir dali não se quis, somente, antagonizar conceitos como ditadura e democracia, censura e liberdade, mas antes contribuir para uma consciência histórica de base humanista e, por isso, clarificadora de "identidades culturais e outras, [que] não são estáticas ou monolíticas, mas dinâmicas e multifacetadas" 
(CONSELHO DA EUROPA, 2018, p. 12) e de versões do passado que podem ser "distorcida[s] e enganadora[s]" (CONSELHO DA EUROPA, 2018, p. 22). Sobretudo porque quando se abordam eventos históricos que em muito se distanciam dos valores democráticos que, hoje, se desejam transversais e sem término, o processo de ensino e de aprendizagem tem 'desculpa' imediata para permitir a formação de um real cidadão "livre, autónomo, responsável e consciente de si próprio e do mundo que o rodeia", além de defensor e respeitador dos "princípios fundamentais da sociedade democrática e [d]os direitos, garantias e liberdades em que esta assenta" (MARTINS et al., 2017, p. 15).

Ressalva-se que esta proposta de atividade apresentada aos alunos foi encarada com particular expectativa e inquietação, pois assumiu contornos distintos de hábitos já instituídos pelo tempo: leitura de uma obra literária na aula de História e Geografia de Portugal, reorganização do espaço de sala de aula para a escuta da história, uso do livro didático somente como lugar de pesquisa, preenchimento orientado de um guião de leitura.

\section{3. "Cruzando histórias..." - construção de um guião de leitura}

Com base nas especificidades do livro escolhido e nos conhecimentos históricos que se quiseram trabalhar na sala de aula, elaboraram-se as tarefas a incluir no guião de leitura. Ou seja, não foi esquecido que se pretendia fazer uma espécie de percurso entre a História de uma Flor e a História de Portugal.

Por um lado, atribuiu-se certa atenção a um texto literário com qualidade estética e formal, ao nível da sintaxe, do léxico, dos recursos linguísticos, por isso mesmo, um contributo para o desenvolvimento de competências de leitura e de escrita fundamentais. Por outro lado, os saberes históricos não se puderam apartar, sendo relevante mobilizá-los de uma forma significativa, ou seja, enquanto aprendizagem que ultrapassa a mera apreensão de alguns factos tidos como mais importantes ou, de outro modo, assumidos como o único ponto de vista histórico.

Por entre uma data ou um nome era necessário equacionar desafios capazes de envolver os jovens estudantes no reconhecimento de certa relevância histórica e da multicausalidade associada aos acontecimentos, na assunção de 
um raciocínio algo questionador ou do lugar que, outrora, outros ocuparam. Sem a expectativa, pois claro, de que uma só iniciativa fosse suficiente para um completo aprimoramento daquela consciência histórica realmente humanista e ponderada.

Assim, consideraram-se as seguintes tarefas, na generalidade ligadas ao preenchimento de determinados espaços, mais ou menos sugestivos, em branco:

Figura 1 - Interação entre a obra literária e os conteúdos/saberes históricos.

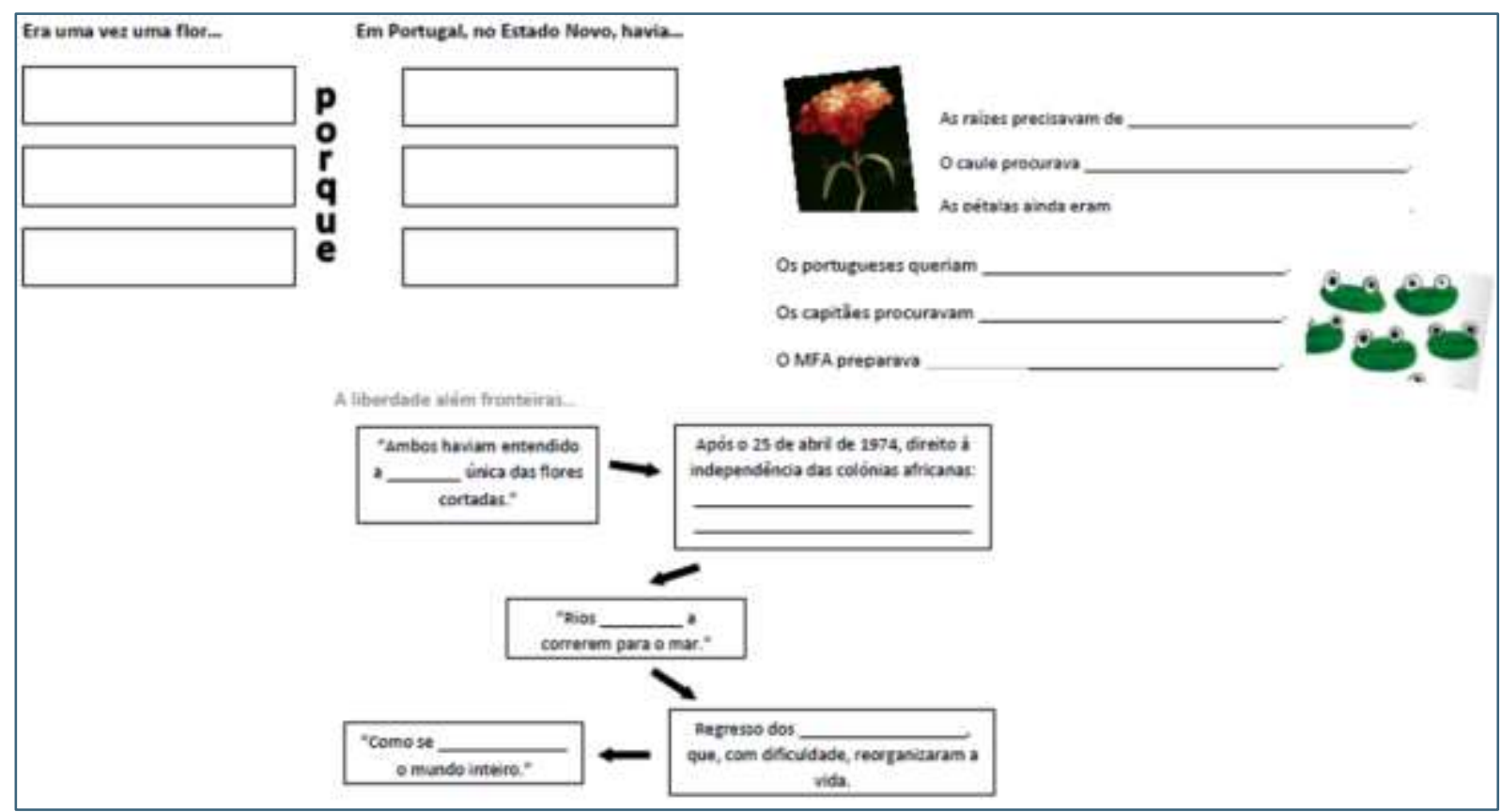

Fonte: Elaborado pelos autores, 2021.

Figura 2 - Uso das metáforas literárias para sistematização de informações históricas (em alguns casos, de cariz substantivo).

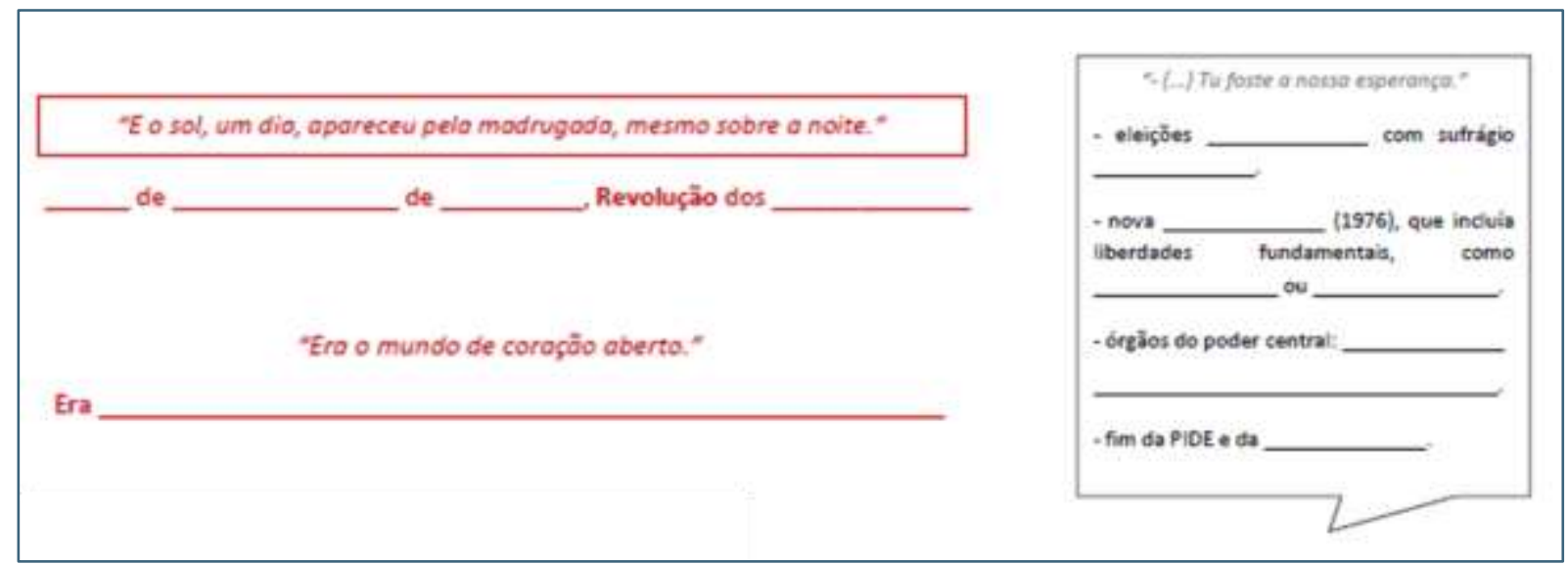

Fonte: Elaborado pelos autores, 2021. 
Figura 3 - Perguntas (mais) diretas, mas para mobilização de competências do pensamento histórico, como a significância ou a causalidade.

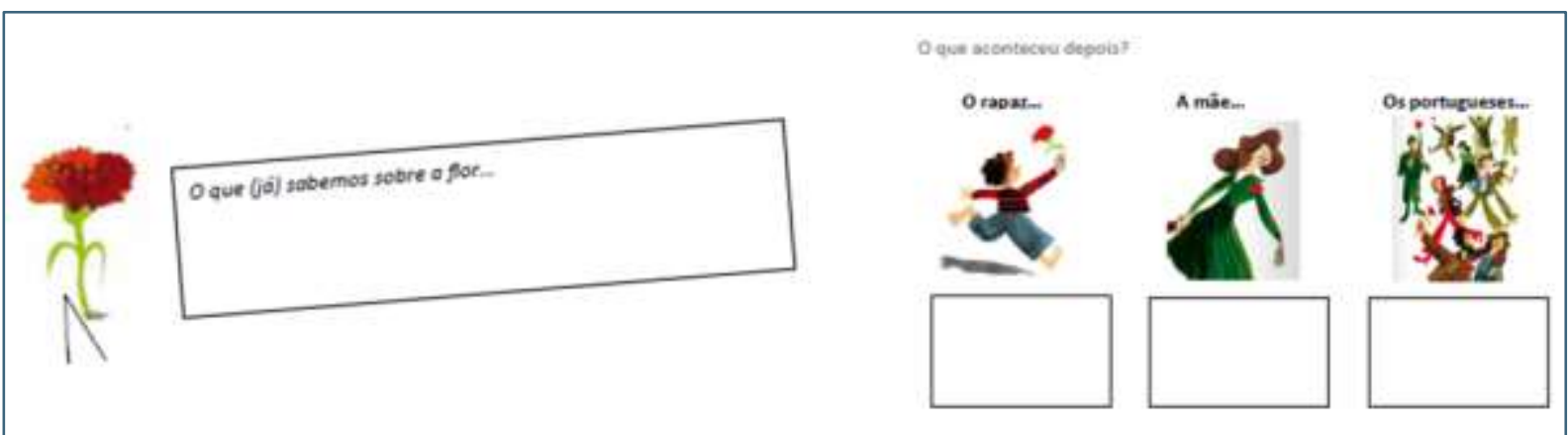

Fonte: Elaborado pelos autores, 2021.

Figura 4 - Identificação de elementos paratextuais para apresentação de conhecimentos prévios.

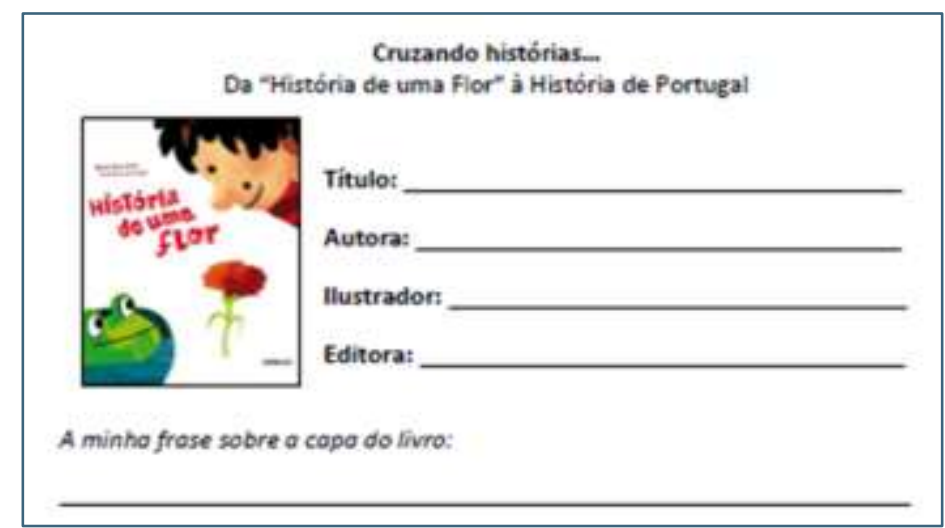

Fonte: Elaborado pelos autores, 2021.

Como se constata pelos exemplos acima, em todo o guião (aqui apresentado na sua totalidade, mas com a ordem das tarefas alterada para uma melhor clarificação do propósito formativo das mesmas) incluíram-se ilustrações retiradas da obra, dada a sua qualidade estética e pertinência para a análise levada a cabo.

Este documento de trabalho, para além de ter sido elaborado em consonância com princípios valorizados no âmbito do ensino e da aprendizagem da História, também recebeu a validação de uma investigadora especialista na área da didática do Português. 


\section{Entre o ensino e a aprendizagem da História: análise e discussão dos dados}

Desde logo, importa salientar que as respostas dos alunos, no geral, evidenciam uma leitura atenta da obra literária e uma mais ténue mobilização dos saberes sobre História. Todavia, não se avançou para a dinamização desta proposta com a expectativa de que, somente pela mesma, os estudantes alcançariam certas destrezas de pensamento ou uma consciência histórica com marcas de particular progressão.

No que concerne aos elementos paratextuais presentes na figura 4 - título, autora, ilustrador, editora -, os mesmos foram indicados, com correção, pelos 14 participantes, que centraram a sua atenção na capa do livro selecionado. Logo a partir daí, pese embora tenham optado por frases simplistas sobre a ilustração observada (A minha frase sobre a capa do livro), mobilizaram os seus conhecimentos prévios sobre a revolução democrática de 1974, associando-lhe o cravo vermelho:
A flor lembra-me o 25 de abril. (a5³)
O menino e um sapo no 25 de abril. (a6)
A flor do 25 de abril de 1974. (a13)

Depois, o paralelo entre a história da Flor e a história de Portugal (Era uma vez uma flor que... | Em Portugal, no Estado Novo havia...), visível na figura 1, escreveu-se com maior diversidade no que ao segundo ponto diz respeito. Se todos os alunos retiraram da obra lida a perceção de uma flor prisioneira da sombra, pobre e num canto escuro, relativamente à vida portuguesa aquando da ditadura salazarista, as ideias históricas perfilhadas nem sempre coincidiram. Ainda assim, por entre referências à pobreza (a7; a11), à censura (a2), à PIDE (a5; a14), à injustiça (a3; a8) ou, somente, à ditadura (a1), constata-se uma generalizada compreensão de um regime político que ocasionava a falta de opinião (a12) e, acima de tudo, a falta de liberdade (a13), por exemplo promovendo eleições que não eram livres (a10).

\footnotetext{
${ }^{3}$ Para garantir o anonimato dos participantes, as suas frases/palavras são identificadas com a letra a (de aluno) e com um número atribuído aleatoriamente a cada um.
} 
Para os 14 alunos, não houve dúvidas na pergunta de preenchimento referente às necessidades de uma flor como o cravo (Figura 1) - humidade, sol, luz ou posição vertical -, nem sobre o pormenor das suas pétalas que, antes, ainda eram pálidas.

Por sua vez, sobre os motivos que aliaram civis, militares e, em concreto, o Movimento das Forças Armadas (MFA) na procura de um outro Portugal, sem restrições às liberdades individuais e sem guerra colonial, também não houve divergências. Aquela relação de causalidade, que não tem de ser linear, percebeu-se quando se lê a continuidade de cada uma das frases apenas iniciadas no documento utilizado (Os portugueses queriam...l Os capitães procuravam...| O MFA preparava...), e mostradas na figura 1. De facto, os portugueses queriam a liberdade (13/14) ou a revolução dos cravos (a3), como todos apontaram; os capitães procuravam cercar o quartel (14) e o MFA preparava um golpe militar (14). Ações políticas e sociais que se consubstanciaram no 25 de abril de 1974, Revolução dos Cravos (Figura 2), saber substantivo essencial para enquadrar qualquer raciocínio (histórico) mais elaborado.

A história de Matilde Rosa Araújo, a seguir, conta-nos a flor vermelha que adquiriu cor e, mais ainda, voz. Por isso, o guião de leitura sugeria a conclusão da frase 'o que (já) sabemos sobre a flor...' (Figura 3) ou, talvez melhor, uma reflexão sobre a transformação (real) operada pela transição entre uma ditadura e uma democracia. Afinal, aquela voz era isso mesmo, mas também muito mais. E, se alguns estudantes não pensaram historicamente e, como tal, limitaram-se ao imediato ficou mais vermelha (a6; a7; a11; a14), ficou iluminada (a1; a10) ou ficou mais bela (a4; a5; a9), cinco deles conseguiram conferir maior significância histórica ao ocorrido. Para os mesmos, então, a flor era, agora, feliz (a2; a5; a11) e, acima de tudo, livre (a3; a8).

Os elementos apontados a seguir dão conta de uma certa capacidade de pesquisa e seleção de informação histórica por parte dos estudantes. Com efeito, autonomamente, foram capazes de utilizar o seu livro didático como fonte para, com critério, completarem os pontos elencados e que correspondem a razões que justificam o facto de as personagens dos sapos terem dito diretamente ao cravo 'tu foste a nossa esperança' (Figura 2). 
A quase totalidade (12/14) apelidou as eleições de livres e o sufrágio de universal, fez referência à Constituição de 1976 e destacou, sobretudo, a liberdade de expressão e a liberdade de opinião como fundamentais. Aliás, o fim da censura (a2) foi, pois, um contributo reconhecido para essa mudança no rumo da História de Portugal. Apenas os órgãos do poder central não se identificaram com tanta assertividade e, como tal, exigiram uma explicação esclarecedora e, mais ainda, ligada ao quotidiano em curso. Também hoje, com regularidade, os jovens cidadãos portugueses ouvem, aqui e ali, alusões diretas ou indiretas ao Governo, à Assembleia da República, ao Presidente da República ou aos Tribunais. E a intertemporalidade que se deseja presente neste processo de ensino e de aprendizagem rapidamente sobressaiu e foi explorada. Sobre cada um dos órgãos do poder central pensaram-se as suas funções e contributos para a vida democrática atualmente em curso.

Perante a perceção de uma rutura (política e social) face à época anterior, o já ultrapassado Estado Novo, importou consolidar-se esta mudança ocorrida. A história da literatura permitiu que a maioria dos alunos (9/14) respondesse à pergunta 'o que aconteceu depois?' (Figura 3). E mostraram compreender que a flor vermelha e com voz não ficou apenas para o rapaz que a colheu, uma vez que ele mesmo foi buscar o cravo para a mãe e ela recebeu a flor. Já no que diz respeito à história do país, todos constataram um bem-estar coletivo face ao acontecido. Pelas suas palavras reveladoras, os portugueses festejaram e colocaram cravos em todos os locais.

Não tiveram qualquer dúvida de que "era o mundo de coração aberto" (ARAÚJO, 2008, p. 24), todavia alcançaram um patamar um pouco acima quando clarificaram tal metáfora historicamente (Figura 2). Assim, incluindo uma ténue consciência crítica na sua análise, entenderam o processo histórico em estudo como incontornável para o decurso da vida nacional. Era...

a liberdade dos portugueses. (a12)

o fim da ditadura. (a8)

esperança, liberdade e paz para todos os portugueses. (a1)

um mundo com liberdade. (a4) 
Por fim, a 'liberdade além-fronteiras' (Figura 1) não foi alheada da atividade. Desta forma, tentou-se uma aproximação à empatia histórica, abordando um assunto tantas vezes esquecido ou branqueado nas salas de aula portuguesas: a guerra colonial. Se, a partir da obra literária, os estudantes compreenderam "a alegria única das flores cortadas" (ARAúJO, 2008, p. 25), pela busca de dados históricos pertinentes ligaram-nas às colónias africanas, agora territórios independentes, nomeando-as uma por uma, ou aferindo que esta consequência da Revolução de abril foi ao encontro do prometido no programa do MFA (a6; a9). Além disso, leram "os rios livres a correrem para o mar" (ARAÚJO, 2008, p. 25) como sinónimo dos retornados (13/14) ou, antes, dos portugueses (a5) regressados para uma vida difícil e a requerer apoio e cooperação.

E, depois, pensaram-nos um pouco mais, no diálogo estabelecido a partir do preenchimento dos espaços em branco, porquanto discutiram também o direito de todos à sua autodeterminação. Em qualquer espaço ou tempo, independentemente da História e sem meias palavras.

\section{Considerações finais}

Com este artigo, procuramos apresentar uma experiência de diálogos (im)prováveis na escola, na sala de aula, no processo de ensino e de aprendizagem, a propósito da História que se pretende ensinar, convocando a Literatura, mais concretamente, a obra literária "História de uma Flor", de Matilde Rosa Araújo, como eixo estruturador para abordar certo momento da História de Portugal. Esses diálogos tiveram como princípio a curiosidade empírica que nos levou a questionar sobre que implicações formativas podem resultar de uma articulação curricular entre a História e a Literatura.

A conceção de ensino de História aqui adotada situa-se na linha daqueles que a perspetivam como saber que estimula a conexão problematizadora entre o presente, o passado e o futuro - com olhos no presente, recuar ao passado para responder a questões que poderão ter eco no futuro (BARCA, 2019b; RÜSEN, 2019) -, valorizando a multiperspetiva, a compreensão da realidade, do mundo, da vida e assumindo relevância inquestionável na formação e educação de cada indivíduo, em particular, e da Humanidade, em geral. A Literatura surgiu, neste 
contexto, como interlocutora para trabalhar o pensamento histórico, pois no centro estava o estudo de um conteúdo histórico.

Com base nos pressupostos apresentados, foi possível desenhar, experimentar e apresentar resultados de uma prática de ensino e de aprendizagem, numa turma do 2. Ciclo do Ensino Básico, assente na interação entre saberes científicos e escolares, com intencionalidade didática e pedagógica, tendo como propósitos formativos/educativos, designadamente, estimular o pensamento divergente, promover a reflexão crítica, potenciar a fruição e a dimensão de jogo, fomentar a resolução de problemas, a partir de enredos narrativos.

Conscientes das limitações e da dimensão da experiência desenvolvida, não pretendemos, nem o pretendêramos antes, provar que, apenas com a proposta apresentada, os alunos desenvolveriam todas as competências e capacidades e alcançariam a consciência histórica que só intervenção pedagógica reiterada, planeada e intencional permite. Não obstante, e feita a ressalva de que o processo levado a cabo constituiu apenas um ponto de partida e poderá servir de mote para a reflexão sobre a relevância, e necessidade, do diálogo entre saberes na escola, na sala de aula, a proposta dinamizada e a sua análise fornecem-nos elementos de reflexão.

Assim, e com base nos resultados obtidos, consideramos poder afirmar que permitem reforçar a vitalidade do diálogo entre a Literatura e a História, não porque se torna mais fácil o acesso ao conhecimento, mas antes porque os dois saberes em interação concorreram, e concorrem, para a promoção de competências e de atitudes que se enquadram na perspetiva mais ampla da educação. Com esta abordagem metodológica procurou-se aproximar os conhecimentos escolares da vida, da realidade dos alunos, a partir das especificidades, diferenças e afinidades da História e da Literatura. Para isso selecionaram-se estratégias e fontes que afinam o olhar e o pensamento, favorecendo uma atitude mais crítica, mais interventiva e cidadã, pela compreensão da informação, seja ela factual ou baseada na ficção, estimulando raciocínios cada vez mais elaborados, mais exigentes, em prol de uma sociedade mais empática, mais participativa, mais democrática e plural (CHAPMAN, 2021). 
Para esta perspetiva de valorização dos saberes em diálogo, em particular no contexto escolar, assumem peculiar relevo a natureza dos materiais utilizados e as atividades que eles suscitam, articulando conhecimentos substantivos e conhecimentos metodológicos. Nesse sentido, foi intencionalmente escolhida uma obra, entre várias possíveis, e a sua compreensão foi ancorada num guião de leitura específico, criado de acordo com o conteúdo histórico a estudar e o conteúdo da narrativa a compreender. Aqui, uma vez mais, a História e a Literatura se articulam porque, para a leitura compreensiva de um texto, é necessário desenvolver competências de seleção de informação, de análise, de inferência, de apreciação crítica, assumindo e defendendo pontos de vista diversos, aprendendo a lidar com diferentes visões sobre o mesmo assunto, que obrigam à descentração de si próprio. E também a forma de ensinar História, na linha que percorre o presente artigo (BARCA, 2019a; LEE, 2016; SCHMIDT; URBAN, 2018), se preocupa com o desenvolvimento de habilidades que capacitem os alunos para a recolha, seleção e análise de fontes, para o contacto com a multiperspetiva histórica, para o desenvolvimento de atitudes de empatia e de argumentação.

História e Literatura encontram-se na escola, como na vida. Através da experiência realizada, este diálogo poderá contribuir para esbater a artificialidade dos reinos que ainda compõem aquela organização (TORRES SANTOMÉ, 2015), para proporcionar situações de aprendizagem mais articuladas e integradas, concorrendo para uma formação cidadã mais ativa, para promover a autonomia crítica e responsável, para uma sociedade comprometida com os Direitos Humanos.

\section{Referências}

APRENDIZAGENS ESSENCIAIS. História e Geografia de Portugal: 6. ano. Lisboa: Direção-Geral da Educação, 2018.

ARAÚJO, Matilde Rosa. História de uma flor. Lisboa: Caminho, 2008.

BARCA, Isabel. A controvérsia em história e em educação histórica. In: VERA, Juan; FERNANDÉZ, José (eds.). Temas controvertidos en la aula: enseñar 
historia en la era de la posverdad. Murcia: Universidad de Murcia, 2019a. p.497511.

BARCA, Isabel. Investigar em educação histórica em Portugal: opções metodológicas. Educar em Revista, Curitiba, v. 35, n. 74, p. 109-126, 2019b. Disponível em https://revistas.ufpr.br/educar/article/view/64403/38487. Acesso em: 10 jan. 2021.

BARDIN, Laurence. Análise de conteúdo. São Paulo: Edições 70, 2011.

BARTON, Keith; LEVSTIK, Linda. Teaching history for the common good. Mahwah: Lawrence Erlbaum Associates, 2004.

BEANE, James A. Integração curricular: a essência de uma escola democrática. Currículo sem Fronteiras, [s.l.], v. 3, n. 2, p. 91-110, 2003. Disponível em: http://www.curriculosemfronteiras.org/vol3iss2articles/beane.pdf. Acesso em: 16 jan. 2021.

BILLIG, Michael. Nacionalismo banal. Madrid: Capitán Swing, 2014.

CHAPMAN, Arthur. Historical interpretations. In: DAVIES, Ian (ed.). Debates in history teaching. Abingdon: Routledge, 2010. p.96-108.

CHAPMAN, Arthur. Introduction: historical knowing and the 'knowledge turn'. In: CHAPMAN, Arthur (ed.). Knowing history in schools. London: UCL Press, 2021. p.1-31.

CHAPMAN, Arthur; GEORGIOU, Maria. Powerful knowledge building and conceptual change research: learning from research on 'historical accounts' in England and Cyprus. In: CHAPMAN, Arthur (ed.). Knowing history in schools. London: UCL Press, 2021. p.72-96.

CONSELHO DA EUROPA. Ensino de qualidade na disciplina de História no século XXI. Estrasburgo: Conselho da Europa, 2018.

COUNSELL, Christine; MCCONNELL, Tony; BURN, Katharine; FOSTER, Rachel. Editorial. Teaching History, London, n. 171, p. 2, 2018.

DAMÁSIO, António. A estranha ordem das coisas. Lisboa: Temas e Debates Círculo de Leitores, 2017.

FLICK, Uwe. El diseño de la investigación cualitativa. Madrid: Morata, 2015.

LEE, Peter. Literacia histórica e história transformativa. Educar em Revista, Curitiba, n. 60, p. 107-146, 2016. Disponível em: 
https://www.scielo.br/j/er/a/kGFY5FDVCVz6J8DJCKwbqcT/?lang=pt. Acesso em: 3 jan. 2021.

LEITE, Carlinda. A articulação curricular como sentido orientador dos projetos curriculares. Educação Unisinos, São Leopoldo, v. 16, n. 1, p. 87-92, 2012. Disponível em:

http://www.revistas.unisinos.br/index.php/educacao/article/view/edu.2012.161.09 /773. Acesso em: 16 jan. 2021.

MÃE, Valter Hugo. Países de crianças. Notícias Magazine, Porto, 11 jan. 2021. Disponível em: https://www.noticiasmagazine.pt/2021/paises-decriancas/cronicas/cidadania-impura/258627/. Acesso em: 11 jan. 2021.

MANGUEL, Alberto. Uma história da leitura. Lisboa: Editorial Presença, 1998.

MANSFIELD, Andrew. Confusion, contradiction and exclusion: the promotion of British values in the teaching of history in schools. The Curriculum Journal, London, v. 30, n. 1, p. 40-50, 2019.

MARTINS, Guilherme Oliveira et al. Perfil dos alunos à saída da escolaridade obrigatória. Lisboa: Direção-Geral da Educação, 2017.

MORGADO, José Carlos; SILVA, Carlos. Articulação curricular e inovação educativa: caminhos para a flexibilidade e a autonomia. In: MORGADO, José; VIANA, Isabel; PACHECO, José (orgs.). Currículo, inovação e flexibilização. Santo Tirso: De Facto, 2019. p. 59-76.

NORDGREN, Kenneth. How to do things with history: use of history as a link between historical consciousness and historical culture. Theory \& Research in Social Education, London, v. 44, n. 4, p. 479-504, 2016.

NORDGREN, Kenneth. Powerful knowledge, intercultural learning and history education. Journal of Curriculum Studies, London, v. 49, n. 5, p. 663-682, 2017.

PORTUGAL. Decreto-Lei n.o 55/2018, de 6 de julho de 2018. Diário da República, [Lisboa], Série I, 129, 6 jul. 2018. Disponível em: https://www.dge.mec.pt. Acesso em: 1 fev. 2021.

ROLDÃO, Maria do Céu; ALMEIDA, Sílvia. Gestão curricular: para a autonomia das escolas e professores. Lisboa: Direção-Geral da Educação, 2018.

ROSALES LÓPEZ, Carlos. Didáctica: innovación en la enseñanza. Santiago de Compostela: Andavira, 2009.

RÜSEN, Jörn. Jörn Rüsen e o ensino da história. Brasil: Editora UFPR, 2010. 
RÜSEN, Jörn. History in context: critical approaches to some basic concepts. In: VERA, Juan; FERNANDÉZ, José (eds.). Temas controvertidos en la aula: enseñar historia en la era de la posverdad. Murcia: Universidad de Murcia, 2019. p. 425440 .

SCHMIDT, Auxiliadora; URBAN, Ana Cáudia. Afinal, o que é educação histórica? Revista Ibero-Americana de Educação Histórica, Curitiba, v. 1, n. 1, p. 7-31, 2018. Disponível em: https://aipedh.files.wordpress.com/2019/07/ribeh_v.1_n.1.pdf. Acesso em: 3 jan. 2021.

SEIXAS, Peter; MORTON, Tom. The big six historical thinking concepts. Toronto: Nelson, 2013.

SILVA, Vítor Aguiar e. Teoria da literatura. Coimbra: Livraria Almedina, 1981.

SMITH, Joe; JACKSON, Darius. Two concepts of power: knowledge (re)production in english history education discourse. In: CHAPMAN, Arthur (ed.). Knowing history in schools. London: UCL Press, 2021. p.152-176.

TORRES SANTOMÉ, Jurjo. Sin muros en las aulas: el currículum integrado. In: GIMENO SACRISTÁN, José (org.). Ensayos sobre el currículum: teoría y práctica. Madrid: Morata, 2015. p. 148-159.

WINEBURG, Sam. Historical thinking and other unnatural acts. Philadelphia: Temple University Press, 2001.

YIN, Robert. Case study research and applications: design and methods. 6. ed. Los Angeles: SAGE, 2018.

ZILBERMAN, Regina. A literatura infantil na escola. 7. ed. São Paulo: Global Editora, 1987.

Universidade do Estado de Santa Catarina - UDESC

Programa de Pós-Graduação em História - PPGH

Revista Tempo e Argumento Volume 13 - Número 33 - Ano 2021 tempoeargumento@gmail.com 